In this text we raise a discussion concerning the model proposed by Michel Foucault in the 1970s. The model purports to examine the organization of the power in modern societies and the relationship between power and visibility. Our proposal is thinking of the model of the Panopticon in a society widely marked and set by the mediatic phase. For that to be possible, reviews of the concept of the public range were done and we tried to understand this new public space, which gains different forms from the advance of the mediatic power.

Keywords: Public Sphere, Panopticon, Media; 


\title{
O panóptico na era da mídia: reconfigurações do modelo de vigilância e controle
}

\author{
Rejane de Oliveira \\ POZOBON
}

Neste texto levantamos uma discussão acerca do modelo proposto por Michel Foucault na década de 1970. O modelo se propunha a analisar a organização do poder nas sociedades modernas e a relação entre poder e visibilidade. Nossa proposta é pensar o modelo do Panóptico numa sociedade amplamente marcada e agendada pela instância midiática. Para tanto, lançamos mão da revisão do conceito de esfera pública e tentamos compreender esse novo espaço público, que ganha diferentes contornos a partir do avanço do poder midiático.

Palavras chave: Esfera Pública, Panóptico, Mídia. 


\section{Proposição inicial}

Sucintamente, podemos dizer que o modelo proposto por Foucault, ainda na década de 1970, evidencia que nas sociedades antigas o exercício do poder estava relacionado com a manifestação pública de força e superioridade de um soberano. O regime de poder propiciava que uns poucos se tornassem visíveis diante de muitos. Nas execuções em praça pública, os rebeldes eram mortos diante de um grande público, uma manifestação espetacular do poder soberano.

O modelo foucaultiano ressalta ainda que, a partir do século XVI, novas formas de disciplina e controle foram se instalando. Escolas, prisões, exércitos e hospitais, entre outras instituições, passaram a empregar, ainda que de forma sutil, mecanismos de poder baseados na observação (controle), no registro, no treinamento e na disciplina. Essa "sociedade disciplinar" promoveu uma inversão no exercício da visibilidade, fazendo com que a visibilidade de poucos diante de muitos da sociedade antiga fosse substituída pela visibilidade de muitos diante de poucos. Ou seja, na "sociedade disciplinar", a força e a superioridade passam a ser medidas pela possibilidade de controle e vigilância.

Para ilustrar essa nova relação entre poder e visibilidade, Foucault (2007) trabalha com a imagem do panopticon ${ }^{1}$, um sistema de poder no qual a visibilidade é um meio de controle. Neste protótipo, os sujeitos não testemunham mais a grandiosidade dos espetáculos, eles próprios são o alvo das atenções.

Hoje, com o avanço do poder midiático, expresso de maneira mais contundente a partir do século XX, percebemos que a relação de poder e visibilidade ganha novos contornos. O desenvolvimento dos meios de comunicação e o espaço que a mídia vem ganhando possibilitam um modelo diferenciado de visibilidade, onde um grupo minoritário de indivíduos consegue aparecer diante de muitos. Neste novo modelo, aqueles que têm o controle social e exercem alguma forma de poder/influência é que são submetidos à visibilidade constante. A diferença entre este modelo e o modelo foucaultiano de visibilidade do mundo antigo é que a visibilidade midiática é, como bem define Thompson, "separada da partilha de um lugar comum e, portanto, dissociada das condições e limitações de uma interação face a face" (THOMPSON, 1998, p.121). 
Nossa hipótese de trabalho, portanto, é que a era da mídia traz consigo uma reconfiguração do modelo proposto por Foucault (2007), retomando o regime de visibilidade em que muitas pessoas vigiam alguns poucos indivíduos, mas trazendo como diferencial a ampliação dos processos de visibilidade e controle.

\section{Novo entendimento de Espaço Público}

Em 1962, quando Habermas conceituou espaço público seu entendimento envolvia a idéia da co-presença de cidadãos num mesmo espaço físico. O pensador propunha que a esfera pública era um espaço de mediação entre o Estado e a sociedade civil. Nesta sociedade, Habermas incluía apenas os homens (excetuando os escravos e os estrangeiros) com nível sócio-econômico que thes permitissem acesso a um nível mínimo de educação.

A influência das análises de Adorno e Horkheimer conduziram Habermas a afirmar que os meios de comunicação seriam responsáveis pela perda da capacidade crítica do público e, conseqüentemente, pelo declínio da esfera pública, uma vez que esta perdera sua atuação crítica.

O modelo proposto pelo estudioso alemão recebeu inúmeras críticas. Thompson (1998) entende que o conceito original de Habermas negligencia a importância de outros discursos que já existiam nos séculos anteriores, discursos estes que não faziam parte da sociabilidade burguesa européia, a exemplo dos movimentos sociais surgidos no início da idade moderna.

Thompson (1998) considera a noção de esfera pública burguesa de Habermas um tanto quanto restrita, visto que esta se limitava ao universo masculino e aos indivíduos que tiveram acesso à educação e aos meios financeiros para dela participar. Além disso, o autor argumenta que a maior fragilidade do conceito inicial de esfera pública está no entendimento de que os receptores midiáticos são consumidores passivos que se deixam encantar pelo espetáculo e se manipular pelos artifícios da mídia.

Ainda na década de 1950, Hanna Arendt já se contrapunha ao modelo racionalista de comunicação do espaço público que o pensador alemão viria a propor, pois a pesquisadora sugere que a opinião depende do juízo dos espectadores e pertence à ordem da 
persuasão. Arendt (2001) reconstitui o percurso de desumanização sofrida pelo homem. Na concepção da filósofa, houve um longo processo de atrofia da condição humana, iniciada, parcialmente, com a constituição da esfera social. Isso, segundo ela, porque esse espaço privilegia o comportamento padronizado, diferentemente do espaço público grego que primava pela diferenciação do ser humano. Arendt afirma que a humanidade de hoje é guiada por padrões de comportamento, o que implica em cerceamento reflexivo.

Nesta mesma linha de pensamento, Gomes (1999) afirma que o enfoque inicial de Habermas subestima a capacidade argumentativa da mídia. Segundo o autor, a mídia, mais do que representar, produz a opinião pública.

O modelo habermasiano foi revisto também pelo seu próprio criador, 30 anos depois de sua concepção, quando o autor acrescentou os novos processos de organização e participação pública dos cidadãos à sua discussão inicial. A partir dos anos 90, Habermas revê, em $O$ Espao pblico 30 anos depois, suas reflexões e reconhece as fragilidades de seu enfoque inicial. O autor passa a aceitar a existência de múltiplas esferas públicas, não estando estas restritas a espaços institucionalizados de participação pública, como a imprensa, o parlamento, entre outros.

\section{O modelo de Habermas: o controle e a circulação do poder}

Para explicar a circulação do poder nas sociedades atuais, Habermas (1997) utiliza-se de um esquema proposto por Bernhard Peters, que organiza os atores sociais em um eixo composto de um centro e vários anéis periféricos. No centro estariam as instituições formais (como parlamentos, agências responsáveis pelas decisões administrativas, legislativas e judiciárias, etc.), composta por atores capazes de influir nos processos decisórios. Próximas a este núcleo estariam esferas autonomamente organizadas, mas intrinsecamente ligadas ao governo (como universidades, associações, fundações, etc.). E, em um terceiro nível, estariam as associações orientadas para a formação da opinião (instituições culturais, grupos de ativistas, etc.). Os atores deste nível são aqueles cuja desigualdade de poder 
faz com que sua prática deliberativa fique limitada à formação da opinião sem alcançar a tomada de decisão.

Além de estabelecer essa distinção, Habermas formula um modelo que articula essas esferas. O autor propõe que, o terceiro nível, por possuir uma maior sensibilidade para a identificação de problemas, mobilizaria o primeiro nível, que se encarregaria de decidir quais das alternativas poderiam ser instituídas e legitimadas. O nível intermediário, por sua vez, é o responsável por transportar as opiniões e as alternativas propostas para o nível decisório.

Mesmo com algumas críticas apontando para a persistência de uma grande lacuna entre os níveis propostos por Habermas, parece inegável a ampliação que o autor traz no que tange ao papel dos meios de comunicação na esfera pública e nos processo deliberativos da atualidade.

A comunicação política mediada na esfera pública pode facilitar processos de legitimação deliberativa em sociedades complexas somente se um sistema mediático auto-regulador adquire independência com relação a seu a seu ambiente social, e se audiências anônimas garantem um feedback entre o discurso informado da elite e uma sociedade civil responsiva (HABERMAS, 2008, p.10).

Recentemente, Habermas (2008) reafirmou a centralidade da mídia na esfera pública, salientando o fato de que ela alimenta os fluxos comunicativos e deliberativos que a sustentam, formulando, a partir de estratégias próprias, articulações entre diferentes falas. Ao revisar o conceito de esfera pública e o lugar nela ocupado pela mídia, Habermas aponta que a instância midiática, ao longo dos tempos, adquiriu um grande poder de publicização e desenvolveu uma capacidade de promover acesso aos conteúdos discursivos que circulam em vários contextos comunicativos, contribuindo para que as audiências possam construir opiniões distintas acerca das questões divulgadas.

Portanto, podemos dizer que, se na década de 1960 Habermas mostrava uma visão redutora dos meios de comunicação, a partir da década de 1990 ele procura reformular sua reflexão e confere à mídia uma função organizadora de opiniões e estruturadora da esfera pública. 


\section{Atualidade da obra habermasiana}

As proposições de Habermas permanecem atuais no que tange ao modo como a produção da informação jornalística é limitada por diversos tipos de constrangimentos externos e internos. Ao considerar o espaço midiático como espaço de circulação de diversas perspectivas, o autor reconhece que os veículos selecionam determinados pontos de vista, priorizando alguns acontecimentos e ignorando outros.

Este argumento vai ao encontro das proposições de diversos autores do campo da comunicação ${ }^{2}$, que afirmam que o poder da mídia manifesta-se a partir do "enquadramento" (GOFFMAN,1999) e do agendamento dos temas que terão direito à existência pública.

Não podemos pensar, entretanto, que a mídia tem total autonomia e independência com relação a outros sistemas, como a economia e a política. Ao contrário, ela passa por uma série de constrangimentos, impostos por instituições públicas e privadas, o que limita a atuação dos profissionais que nela atuam.

Visualizamos aí uma dupla lógica de funcionamento da mídia: ao mesmo tempo em que contribui para o alargamento e a construção de espaços de discussão está submetida às lógicas do mercado e das desigualdades de poder.

O que é inegável é a importância que a mídia assume ao agendar os acontecimentos que ganharão espaço na esfera pública. Ao mesmo tempo em que agenda os acontecimentos, a mídia também propõe um significado para estes eventos, oferecendo interpretações e formas específicas para seu entendimento.

Mas é preciso ter cautela. Não podemos esquecer que a construção social da realidade não se constitui em uma prática exclusiva dos meios de comunicação, pois os atores sociais estão vinculados a outras tantas instituições que não apenas a instituição midiática e constroem múltiplas formas de mediação social. Ao jornalista cabe, portanto, recolher os acontecimentos relevantes e atribuir-lhes sentido. Embora essa construção dependa, como já é sabido, do receptor e das inúmeras mediações sociais.

\section{O Processo de construção da notícia}

A hipótese do agendamento ${ }^{3}$ parte da constatação do "poder que (através da sua capacidade simbólica) os meios de comunicação 
de massas exercem para influenciar e determinar o grau de atenção que o público dedica a determinados temas expostos à atenção e ao interesse colectivos" (SAPERAS, 1993, p.54) e hoje se desloca de um modelo que enfatizava as causas e os efeitos dos medias sob a sociedade para um entendimento de um poder midiático que, embora seja bastante significativo, apresenta limites e imprime ressonâncias na esfera pública.

No processo de construção da notícia, as escolhas orientadas pela aparência que a realidade assume para o jornalista, assim como as convenções que moldam a percepção deste profissional da imprensa, podem ser denominadas de enquadramentos (GOFFMAN, 1999). Estes enquadramentos midiáticos se constroem a partir de acontecimentos e podem ser observados a partir de metáforas, exemplos, imagens, formas de discurso etc... Trata-se de um modelo interpretativo do acontecimento que se refere a idéias, temas e linguagens que compõem o repertório cultural do público para o qual o jornalista está falando ou escrevendo.

Um fator relevante, no que se refere ao papel do jornalista na construção dos enquadramentos midiáticos, é que estes constroem as notícias enquadrando os fatos a partir de códigos culturais, regras sociais e valores-notícias pertencentes à cultura jornalística. Assim sendo, a notícia, enquanto um mapa que o jornalista constrói para mostrar a realidade, é uma visão partilhada e enquadrada do acontecimento, feita a partir de critérios de noticiabilidade que explicitam as ideologias e as marcas identitárias do campo jornalístico.

Com isso, percebemos que o jornalismo é marcado pelo ethos profissional de seus membros. Movimenta, assim, um conjunto de normas, valores e rituais que servem de base para as construções noticiosas, apresentando linguagens e saberes próprios. Ao relatar ou interpretar uma fala, o jornalista realiza isso segundo as regras do processo de produção da empresa jornalística, expressas nas suas rotinas, mas, também, segundo um habitus e um ethos profissional próprio, ou seja, uma forma de ver, pensar e agir comum a este grupo.

A origem dos conceitos de habitus e ethos está na ação social, originária da relação entre agentes sociais. Essa relação, por sua vez, é determinada por uma regra de conduta (um ethos) que significa a visão de mundo desses agentes e fornecerá subsídios para a interpre- 
tação de cada ação. Cada grupo social (do qual esses agentes fazem parte) tem habitus específicos que são configurados ao longo da prática social e que conformam respostas espontâneas para situações equivalentes. Bourdieu define o habitus como

um sistema de disposições duráveis, estruturas estruturadas predispostas a funcionarem como estruturas estruturantes, isto é, como princípio gerador e estruturador das práticas e das representações que podem ser objetivamente "reguladas" e "regulares" sem ser o produto da obediência a regras, objetivamente adaptadas ao seu fim sem supor a intenção consciente dos fins e o domínio expresso das operações necessárias para atingi-los e coletivamente orquestradas sem ser o produto da ação organizadora de um regente (BOURDIEU, 1994, p.61)

Focando a compreensão do habitus para o fazer jornalístico, encontramos os estudos de Warren Breed (1999), onde o autor analisa o profissional de jornalismo no contexto da organização para a qual trabalha e salienta a importância que os constrangimentos organizacionais assumem nas notícias por ele construídas. A questão do habitus, pensada de acordo com a teoria deste autor, nos levaria a entender que o jornalista conforma-se mais com as normas da política editorial da empresa jornalística do que com qualquer crença pessoal ou de sua formação. Para Breed (1999) o jornalista vai sendo socializado na política editorial da empresa por meio de recompensas e punições. É nesse sentido que as rotinas produtivas seriam grandes (con) formadoras de habitus, pois este passa a ser cristalizado nas condutas e nos processos cotidianos de sociabilização. O habitus funcionaria como uma espécie de materialização da memória coletiva, o que, de certo modo, garante sua reprodução. Isso, contudo, não se dá de modo automático, pois é marcado pelas ações individuais e coletivas dos atores que vão conformando seus modos de pensar e agir.

Essa compreensão, no entanto, é ampliada por alguns autores que também estudam a questão. De acordo com Barbara Phillips (1999) as notícias dependem de certos hábitos mentais dos jornalistas, que provém da sua formação e orientação prática. Conforme esta perspectiva, o habitus jornalístico resulta, em grande medida, do processo histórico de profissionalização dos trabalhadores de imprensa. É neste sentido que os jornalistas constituem uma comunidade interpretativa, terminologia proposta por Zelizer (1993) e frequentemente trazida por Traquina (2004a). A noção implica que os jornalistas possuem "um 
enquadramento de referência partilhado para trabalhar" (ZELIZER, 1993), e considera o jornalismo não só como profissão, mas também como comunidade interpretativa, unida pelo seu discurso partilhado e pelas interpretações coletivas de acontecimentos públicos relevantes.

Um entendimento comum nos diferentes estudos que trabalham esta noção é pensar o habitus como um produto da história, um sistema aberto que afeta e, ao mesmo tempo, sofre implicações das experiências coletivas. Em outras palavras, do mesmo modo como as condutas individuais são determinadas por um habitus coletivo, este coletivo também sofre as implicações das ações individuais dos agentes. É nesse sentido que Barros Filho e Martino (2003), na obra "O habitus na comunicação", definem o habitus como uma "subjetividade socializada", cujas categorias de percepção e de apreciação (os sistemas de referência) são o produto da história coletiva e, ao mesmo tempo, individual. Ao contrário dos cálculos científicos, cujas probabilidades são construídas de maneira metódica, com base nas experiências controladas e em regras definidas, a avaliação subjetiva de uma ação determinada faz intervir lugares comuns, preceitos éticos e, mais profundamente, princípios inconscientes do ethos.

Nesta direção, partimos do entendimento de que as práticas dos jornalistas se ancoram no habitus e tendem a reproduzir regularidades emanadas de um princípio gerador, ajustando-se às exigências de uma dada situação. Cada agente, tendo ou não consciência desse fato, é um produtor de sentido cujas ações são resultado da cristalização de práticas socialmente aceitas. A partir dessa reflexão, podemos dizer que o habitus é também um processo de mediação, que faz com que as práticas individuais de um agente sejam "objetivamente orquestradas" (BOURDIEU, 1994, p.73) Essa proposição de Bourdieu, ganha aplicabilidade nesta reflexão ao pensarmos o habitus como uma matriz comum aos profissionais do jornalismo, que orientam os critérios de noticiabilidade postos em ação para selecionar e construir a notícia.

\section{Demandas, grupos e acontecimentos com direito à existência pública}

Historicamente, várias construções teóricas já tentaram explicar os critérios que levam o jornalista a escolher, entre os inúmeros fatos 
que ocorrem diariamente no mundo, aqueles que são considerados noticiáveis. Wolf (2002) define o conceito de noticiabilidade como a aptidão de um acontecimento para tornar-se notícia. Segundo o autor, a noticiabilidade pode ser definida como o conjunto de requisitos que são exigidos dos acontecimentos para que eles possam garantir o direito à existência pública. Para garantir o status de notícia, o acontecimento precisa ter determinados atributos, que o autor denomina de valores-notícia. A partir dessa proposição de Wolf, podemos dizer que, a noticiabilidade é construída por meio de um conjunto de valores dados às notícias, tais como: excepcionalidade, sensacionalismo, ausência de ambiquidade etc...

De posse desta informação, as fontes tratam de se conformar a estes critérios de noticiabilidade. Isso nos possibilita dizer que a midiatização, pensada a partir dos critérios de noticiabilidade, se dá também na recepção, no momento em que o receptor internaliza os valores-notícias instituídos pelo campo midiático. De certo modo, isso vai implicar também nos temas agendados para circular na esfera pública.

Para problematizarmos essa questão e entendermos melhor como se dá a construção dos critérios de noticiabilidade, traremos aqui algumas proposições teóricas que podem nos ajudar a compreender como tais práticas e rotinas jornalísticas se processam e passam a configurar a construção noticiosa. Primeiramente, tentemos apreender o que faz um acontecimento virar notcia. Se pensarmos que diariamente ocorrem milhares de acontecimentos no mundo, porque somente alguns poucos eventos são selecionados para ganhar o "status" de notícia? Por que alguns acontecimentos são notícia para determinados meios enquanto em outros os mesmos nem chegam a ser mencionados? O que leva um fato a ser percebido como relevante? Os fatos podem passar despercebidos por não terem um enquadramento que permita ser observado como um acontecimento notável?

Uma das características mais mencionadas para tornar um evento "noticiável" é a sua excepcionalidade. Mouilland (2002, p.307) cita a famosa frase de Amus Cummings, ex-editor do New York Sun, para exemplificá-la: "se um cachorro morde um homem, não é notícia, mas se um homem morde um cachorro, é notícia". Dessa maneira, quanto menos previsível for o fato, maior é a 
chance de se tornar notícia. Mas, obviamente, essa não é a única característica que transforma um acontecimento em uma notícia potencial. Wolf (2002) utiliza o conceito de noticiabilidade ${ }^{4}$ para descrever os atributos (ou, como denominou o autor, os valoresnotícia) necessários para que um acontecimento se torne notícia. Entretanto, seria demasiadamente simplificador tentar entender a seleção das notícias somente como uma escolha pessoal do jornalista ou do meio que este representa. Trata-se de uma questão muito mais ampla, que acontece ao longo do processo produtivo, onde uma diversidade de critérios, normas, valores e rituais acabam se relacionando com a própria noticiabilidade dos fatos.

Buscando ampliar a análise dos critérios de noticiabilidade, Christa Berger (2002) escreve um artigo observando a "passagem" do acontecimento à notícia. A autora salienta que o acontecimento deve ser compatível com a estrutura editorial, ou seja, deve "caber" na ideologia do jornal. A este critério, Berger (2002) acrescenta a aprovação do anunciante e a apreciação do leitor, para completar o círculo de noticiabilidade na mídia.

Um último fator de noticiabilidade é levantado por Rodrigues (1993). Embora não utilize essa nomenclatura, o autor fala que um dos critérios de noticiabilidade está associado à função mediadora da mídia. Ao assumir o papel estratégico de apresentar/divulgar os fatos anunciados pelas demais instituições, ou, nas palavras de Goffman, os "enquadramentos" da realidade, a mídia aponta as estratégias de noticiabilidade que as instituições devem lançar mão para se adequar às exigências do campo midiático. A mídia deixa, então, de somente intermediar vozes e falas e passa a selecionar, interferir, ganhando um poder de decisão que, de alguma forma, foi outorgado pelas demais instituições.

O acontecimento percorre um longo caminho até tornar-se notícia e ser publicado na mídia. Em nosso entendimento, é possível pensar que a notícia, e mais especificamente sua produção, é um processo que se inicia com um acontecimento. Aqui um importante ponto a ressaltar: esse acontecimento, mesmo sendo gerado por fenômenos externos ao sujeito, não adquire sentido à margem desse sujeito. $\mathrm{O}$ acontecimento passa a produzir sentido a partir da percepção dos fenômenos externos pelos sujeitos.

Assim, poderíamos pensar o acontecimento como uma 
mensagem recebida e a notícia como uma mensagem emitida, ou seja, "el acontecimiento es un fenómeno de percepción del sistema, mientras que la noticia es un fenómeno de generación del sistema" (ALSINA, 1989, p.91). Isso significa que "todo hecho social es potencialmente acontecimiento para los mass media y toda noticia es potencialmente un acontecimiento para la sociedad". O autor de "La construcción de la noticia" trabalha o conceito de acontecimento focado na questão da ruptura da lógica sistêmica onde se situam os indivíduos.

A abordagem proposta pelo autor, no entanto, pouco enfatiza a dimensão constitutiva da produção noticiosa enquanto uma prática que, ao identificar essa variação sistêmica, realiza um recorte da realidade, atribuindo-lhe características próprias. A obra de Alsina também não discute o fato de que, esse novo acontecimento, agora contado pelos medias, a partir de um formato próprio, não é mais o mesmo acontecimento percebido como alteração sistêmica. Esses acontecimentos que rompem a ordem social são eventos em construo, ou seja, deixam margens de significação em aberto e que serão apropriadas pelos sujeitos durante os processos de intercâmbio com os diferentes campos sociais com os quais entrarão em contato.

A partir da percepção de uma construção coletiva dos fenômenos sociais, nos aproximamos da compreensão de Rodrigues (1993) acerca do discurso jornalístico e da construção noticiosa. O autor defende que este não se reduz a uma representação da realidade, pois se torna parte, constrói situações da vida social. "Ao relatar um acontecimento, os medias, além do acontecimento relatado produzem ao mesmo tempo o relato do acontecimento como um novo acontecimento que vem integrar o mundo" (RODRIGUES, 1993, p.31).

Como podemos observar, a construção da notícia não é um processo simples, isolado, ao contrário, trata-se de uma atividade complexa e que, segundo Alsina (1989, p.14) "se realiza de forma industrial en el seno de una instituición reconocida socialmente". Alsina (1989) trabalha uma perspectiva sobre a produção jornalística na qual a notícia assume um papel de criação de uma realidade específica, entendida como pública. Para o pesquisador, "notícia é uma representação social da realidade cotidiana produzida 
institucionalmente e que se manifesta na construção de um mundo possível" (ALSINA, 1989, p.185).

A definição proposta pelo autor, além de considerar a notícia como um produto da industrialização, trabalha sua função de mediação. Essa mediação se dá entre o campo midiático e o campo onde o acontecimento se deu. Isso significa dizer que, não basta detectar o acontecimento, este deve ser discursivamente construído e posteriormente veiculado. Nesse sentido, poderíamos inferir que, enquanto o acontecimento constrói a notícia (por ser seu referente) a recíproca também é verdadeira, ou seja, a notícia também constrói o acontecimento, pois este também é um produto do processo de produção. Outro fator que faz com que a notícia também construa o acontecimento é que, na medida em que esta produz ressonâncias na esfera pública, acaba incidindo e ressignificando o acontecimento em questão e os acontecimentos posteriores que serão gerados a partir da entrada da mídia neste circuito.

\section{Vozes e falas presentes no campo midiático}

Várias são as falas que operam no território dos medias. Existe a fala do próprio jornal, que é específica e majoritária, e as falas que comparecem porque o jornal permite que estejam em sua tessitura, são "autorizadas". Mesmo assim, essas falas deixam marcas de outros campos. Wolf (2002) argumenta que as fontes são selecionadas a partir das exigências dos procedimentos produtivos e acabam refletindo a estrutura social e de poder existentes.

Inicialmente, sabemos que qualquer pessoa pode ser fonte e fornecer informações. No entanto, ser cultivada enquanto tal significa que há uma conversão de interesses entre esta fonte e o profissional do campo jornalístico. Esta relação baseia-se na confiança e em interesses de trocas que são específicos, por esse motivo, ao mesmo tempo em que envolve atores dependentes um do outro ela não deixa de ser conflituosa, pois abarca interesses divergentes.

A diversidade de fontes é uma das questões que incide nas rotinas produtivas do jornalismo. Fontcuberta (1993), ao 
comentar a forte presença de fontes institucionais na mídia, explica que essa presença é justificada, principalmente, pelo fato de que tais fontes, além de terem "certificado de credibilidade", "isentam" o jornalista de procurar a informação5, visto que as próprias instituições Ihes fornecem tais elementos. $\mathrm{Na}$ concepção de Hall et al (1999), a preferência dada pelos meios de comunicação às fontes institucionais colabora para o desenvolvimento do papel ideológico dos medias, pois acaba construindo uma imagem da sociedade representativa dos interesses destas fontes. Para Henn (2002), a falta de diversidade de fontes pode contribuir para a formação de um outro problema: uma homogeneidade nas abordagens jornalísticas. Embora as assessorias de comunicação tenham o propósito de fornecer subsídios para o trabalho jornalístico, muitas vezes acabam por substituí-lo, tendo em vista a grande tendência dos medias em aceitar o que está sendo ofertado pelos gabinetes ou pelas agências de notícias.

Como podemos perceber, as rotinas produtivas, de certa maneira, regulam e determinam a prática jornalística. Além do processo de seleção de fontes, outros fatores, tais como tempo e espaço, também incidem nas rotinas produtivas do fazer jornalístico. A estruturação do tempo em uma redação de um jornal impresso, por exemplo, que na maioria das vezes vai do início da manhã ao início da tarde para a apuração dos fatos, é um dos motivos que explica o aumento no grau de noticiabilidade para aqueles acontecimentos registrados neste período de tempo.

Bourdieu (1997, p.40) salienta que, por ser baseada no fator tempo, a prática jornalística não favorece o pensar. A incapacidade de fazer reflexões mais aprofundadas em um curto espaço de tempo faz com que os jornalistas optem por "idéias feitas", o que facilita o processo de recepção, mas, por outro lado, inibe uma construção mais aprofundada. Na mesma linha, Alsina (2001, p.75) afirma que "el proprio trabajo periodístico tiene un tiempo de producción rápido que no siempre permite una autoreflexión y una autocrítica sobre el proprio discurso".

Isso talvez explique porque grande parte da mídia se detém mais na cobertura de acontecimentos do que problemáticas. 
Traquina (2004b, p.111) afirma que "o ritmo do trabalho jornalístico exige uma ênfase sobre acontecimentos e não sobre problemáticas". Segundo o autor, os acontecimentos estão encerrados na "teia da facticidade" do tradicional lead noticioso (quem? o quê? quando? onde? como? porquê?). Já as problemáticas exigem um poder de resposta por parte do campo jornalístico, exigem meios para fazer a cobertura de algo não definido no espaço nem no tempo.

Essas reflexões nos apontam a "dimensão cultural das notícias" (SCHUDSON, 1999). Essa noção resulta da análise de que as notícias são produzidas por sujeitos que operam num sistema cultural. Isso significa dizer que os jornalistas não são simples observadores e sim participantes ativos na construção da realidade. Como membros de uma determinada cultura, os jornalistas constroem as notícias de acordo com uma cultura específica. Essas notícias refletem o ethos especializado da cultura jornalística e passam, então, a serem representativas desta cultura, pois ajudam na compreensão de seus valores e sentidos.

\section{O panóptico na era da mídia}

A partir desta breve revisão teórica, sugerimos que vivenciamos hoje uma inversão do modelo de "sociedade disciplinar" proposto por Foucault (2007). Inversão esta que não se aproxima do modelo foucaultiano de visibilidade do mundo antigo, visto que apresenta uma distinção de fundamental importância que é a independência da interação presencial. Portanto, a proposição do panptico da era miditica retomaria a idéia de uns poucos sendo vigiados por muitos, mas acrescentaria a esse modelo a possibilidade desta vigilância ser realizada a partir de uma infinidade de recursos oferecidos pelas novas tecnologias de informação e pelo avanço do poder midiático ${ }^{6}$.

Seguramente, a mídia tem o poder de retirar várias demandas e atores sociais da condição de invisibilidade, exercendo uma função mediadora. A visibilidade possibilitada pela mídia é importante não só para o sistema decisório, que ocu- 
pa um nível central, como também para os atores que fazem parte dos níveis mais periféricos.

É fato, entretanto, que neste espaço de visibilidade mediada existem grandes assimetrias no que tange às possibilidades de validação e regulação das mensagens. Grupos mais organizados, movimentos sociais e ONGs possuem maior possibilidade de instaurarem agendas públicas de discussão de suas necessidades.

Inversamente, grupos politicamente desarticulados têm suas demandas constantemente restringidas às dinâmicas comunicativas de contextos privados ou "alternativos" que fazem parte das margens do processo deliberativo (DOWNING, 2001).

Primeiramente, é preciso destacar que nem todas as vozes estão representadas no espaço da visibilidade mediada. No caso da demanda do grupo receber destaque na instância midiática, vale ainda lembrar que o acesso às informações não assegura às audiências uma disponibilização de todas as perspectivas relacionadas às questões que estão sendo discutidas. $O$ acesso a diferentes enunciados não implica que estes foram selecionados a partir de um processo democrático de inclusão.

Podemos dizer que, uma das principais contribuições que a mídia oferece ao processo deliberativo é a disponibilização de uma pluralidade de informações. Ao expor informações qualificadas, a mídia disponibiliza pontos de vista diferenciados para que a audiência possa formar seu próprio juízo e interpretar a informação recebida a partir das suas experiências de vida.

Assim, a publicização de uma determinada questão no espaço da visibilidade mediada permite sua disseminação a um público múltiplo e heterogêneo, viabilizando a capacidade de uma interpretação crítica e diversificada da audiência. É neste sentido que, hoje, a esfera pública converte-se numa arena de entrecruzamento de diferentes demandas, proposições e pontos de vista, mediada pelo poder e pelo discurso da mídia.

\section{Notas}

1. Modelo de penitenciária proposto em 1791, por Jeremy Bentham. Tratava-se de uma construção circular com uma torre de observação ao centro. Neste modelo, um único supervisor poderia controlar uma multiplicidade de detentos. Sabendo que suas ações eram constantemente visíveis, os detentos se comportavam como se estivessem sendo 
observados a todo o momento, o que nem sempre era necessário. A permanente visibilidade garantia a manutenção do exercício do poder (Thompson, 1998).

2. Traquina (2004), Wolf (2002), entre outros.

3. Proposta por Maxwell McCombs e Donald Shaw, no artigo "The agenda-setting functions of the mass-media", publicado na revista acadêmica Public Opinion Quarterly. Os autores do agenda setting estruturaram essa hipótese a partir dos estudos de Bernard Cohen e afirmavam que os medias podem não dizer às pessoas como pensar, mas dizem às pessoas no que pensar (Saperas, 1993; Traquina, 2004a e 2004b).

4. Conjunto de critérios, operações e instrumentos com os quais os órgãos de informação enfrentam a tarefa de escolher, quotidianamente, entre um número imprevisível e indefinido de factos, uma quantidade finita e tendencialmente estável de notícias." (WOLF, 2002, p.190)

5. Quando maior for a posição do indivíduo, maior será a confiança na sua autoridade. Traquina (2004a) chama isso de "hierarquia da credibilidade".

6. Alguns programas televisivos (tais como realities shows e quadros de intimidade de artistas ou celebridades) e recursos da web (dentre eles o recente twitter) traduzem perfeitamente esse modelo.

\section{Referências}

ALSINA, Miguel Rodrigo. La construccin de la noticia. Buenos Aires: Paidós, 1989.

ARENDT, Hannah. A condio humana. 10ed. Rio de Janeiro: Forense Universitária, 2001.

BARROS FILHO, Clóvis; MARTINO, Luiz Mauro Sá. O habitus na comunicao. São Paulo: Paulus, 2003.

BERGER, Christa. Do jornalismo: toda notícia que couber, o leitor apreciar e o anunciante aprovar, a gente publica. In: MOUILLAND, Maurice; PORTO, Sérgio.Dayrell. (org). O Jornal: da forma ao sentido. 2ed. Brasília: Editora da UNB, 2002.

BREED, Warren. Controlo social na redacção: uma análise funcional. In: TRAQUINA, Nelson. Jornalismo: questões, teorias e "estórias". 2ed. Lisboa: Vega, 1999.

BOURDIEU, Pierre. Esboços de uma teoria da prática. In: ORTIZ, Renato (org). Sociologia. 2ed. São Paulo: Ática, 1994.

DOWNING, John D. H. Mdia Radical: rebeldia nas Comunicações e Movimentos Sociais. São Paulo: SENAC, 2001.

FONTCUBERTA, Mar de. La noticia: pistas para percibir el mundo. Barcelona: Paidós, 1993.

FOUCAULT, Michel. Vigiar e Punir. 36ª̣ed. São Paulo: Vozes, 2007.

GOFFMAN, Erving. A representao do eu na vida cotidiana. 8ed. Petrópolis: Vozes, 1999. 
GOMES, Wilson. Esfera pública: política e media II. In: Prticas discursivas na cultura contempornea. Rio Grande do Sul: Unisinos, 1999.

HABERMAS, Jürgen. Comunicação política na sociedade mediática: o impacto da teoria normativa na pesquisa empírica. In: Revista Lbero - Ano $X I$ - no 21 - Jun 2008 (p. 9-22).

Tempo Brasileiro, 2003

Mudana estrutural da esfera pblica. Rio de Janeiro:

O Espaço Público 30 anos depois. Caderno de Filosofia e Cincias Humanas. Ano III - n. 12 Abril/99 - Unicentro/BH, 1999.

Direito e democracia: entre facticidade e validade. Vol II. Trad. Flávio Beno Siebeneichler. Rio de Janeiro: Tempo Brasileiro, 1997.

MARQUES, Ângela Cristina Salgueiro. Os meios de comunicação na esfera pública: novas perspectivas para as articulações entre diferentes arenas e atores. In: Revista Lbero - Ano XI - no 21 - Jun 2008 (p. 23-36).

HALL, Stuart et all. A produção social das notícias: o mugging nos medias. In: TRAQUINA, Nelson. Jornalismo: questões, teorias e "estórias". 2.ed. Lisboa: Vega, 1999.

McCOMBS, Maxwell E; SHAW, Donald L. A evolução da pesquisa sobre o agendamento: vinte e cinco anos no mercado de idéias. In: TRAQUINA, Nelson. O poder do jornalismo: análise e textos da teoria do agendamento. Coimbra: Minerva, 2000.

PHILLIPS, Bárbara. Novidade sem mudança. In: TRAQUINA, Nelson. Jornalismo: questões, teorias e "estórias". 2ed. Lisboa: Vega, 1999.

RODRIGUES, Adriano Duarte. O acontecimento. In: TRAQUINA, Nelson (org.). Jornalismo: questões, teorias e estórias. Lisboa: Vega, 1993.

SAPERAS, Enric. Os efeitos cognitivos da comunicao de massas: as recentes investigações em torno dos efeitos da comunicação de massas: 1970/1986. Trad. Fernando Trindade. Porto: Asa, 1993.

SCHUDSON, Michael. A política da forma narrativa: a emergência das convenções noticiosas na imprensa e na televisão. In: TRAQUINA, Nelson. Jornalismo: questões, teorias e "estórias". 2ed. Lisboa: Vega, 1999.

THOMPSON, John. A mdia e a modernidade: uma teoria social da mídia. Petrópolis: Vozes, 1998.

TRAQUINA, Nelson (org). Teorias do Jornalismo: porque as notícias são como são. Florianópolis: Insular, 2004.a

Florianópolis: Insular, 2004.b A tribo jornalstica: uma comunidade transnacional.

WOLF, Mauro. Teorias da comunicao. 7ed. Lisboa: Presença, 2002. 
ZELIZER, Barbie. Journalists as interpretative community. In: Critica/ Studies in Mass Comunication. V10, 1993.

\section{Rejane de Oliveira Pozobon}

Doutora em Ciências da Comunicação. Professora Adjunta do Departamento de Ciências da Comunicação da Universidade Federal de Santa Maria/RS. Coordenadora do Laboratório de Pesquisa de Opinião Pública (UFSM). Professora pesquisadora do Grupo de Estudos e Pesquisas em Arte, Educao e Cultura (CNPq) e do Grupo de Pesquisa Estudos de Jornalismo (CNPq).

E-mail:rejane.op@terra.com.br 